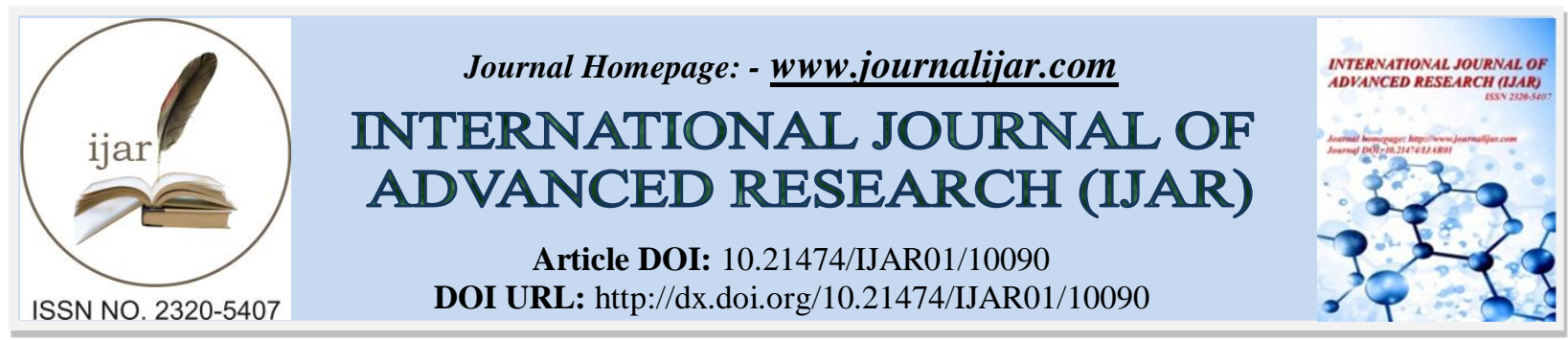

RESEARCH ARTICLE

\title{
SIGNIFICANCE OF RAISED SERUM URIC ACID LEVELS IN PATIENTS WITH CHRONIC KIDNEY DISEASE.
}

Dr. Venkateswarlu ${ }^{1}$ and Dr. Padma Vijaya Sree ${ }^{2}$.

1. Assistant Professor, Dept of Biochemistry, Kurnool Medical College, Kurnool.

2. Professor and HOD, Dept of Biochemistry, Kurnool Medical College, Kurnool.

\section{Manuscript Info}

\section{Manuscript History}

Received: 14 September 2019

Final Accepted: 16 October 2019

Published: November 2019

Key words:-

Chronic Kidney Disease, Uric Acid

,Cardiovascular disease.

\section{Abstract}

Background: Hyperuricemia is common in chronic kidney disease (CKD). The present study evaluated the associations between baseline serum uric acid levels with mortality and end-stage renal disease (ESRD). Chronic kidney disease (CKD) is a serious condition associated with premature mortality, decreased quality of life, and increased health- care expenditures. Chronic kidney disease occurs when one suffers from gradual and usually permanent loss of kidney function over time.

Material and Method: This is a prospective observational study conducted in Nephrology Dept affliated to Biochemistry Dept, Govt.General Hospital,Kurnool From June 2018 to may 2019. In this study, 158 CKD patients were studied with detailed clinical and laboratory examination and divided into two groups: one group included $60 \mathrm{CKD}$ patients with raised serum uric acid and another group containing $98 \mathrm{CKD}$ patients with normal serum uric acid. Both groups were age matched.

Results: In our study, prevalence of raised serum uric acid in CKD patients was found to be $38.4 \%$. It is observed that, CKD patients with raised serum uric acid were predominantly male and presented mainly in later part of life. There is statistically significant $(\mathrm{p}<0.05)$ positive correlation is found between serum uric acid and stages and severity of CKD, hypertension, diabetes mellitus, serum BUN, serum creatinine, urine albuminuria, anaemia, cardiovascular disease, mortality and negative correlation with eGFR .

Conclusion: In CKD patients, higher serum uric acid levels were associated with higher degree of renal dysfunction, hypertension, diabetes, urine albuminuria, anaemia, cardiovascular disease and mortality. It is found that most common cause of mortality in CKD patients with raised serum uric acid was cardiovascular disease/events.

Corresponding Author:-Dr.Venkateswarlu.

Address:-Assistant Professor, Dept of Biochemistry, Kurnool Medical College, Kurnool. 


\section{Introduction:-}

Hyperuricemia is common in chronic kidney disease (CKD). The present study evaluated the associations between baseline serum uric acid levels with mortality and end-stage renal disease (ESRD). Chronic kidney disease (CKD) is a serious condition associated with premature mortality, decreased quality of life, and increased health- care expenditures. Chronic kidney disease occurs when one suffers from gradual and usually permanent loss of kidney function over time. This happens gradually, usually over months to years.1

The lineage of kidney disease as a subject of study generally is traced to 1827 , when Richard Bright (1789-1858) described his eponymous disease of the kidneys in albuminuricdropsical patients who died in kidney failure. By middle of 19th century, kidney disease was defined, it's diagnosis by urinanalysis was established, and it's structural changes were characterized, but speciality of nephrology went unborn and patients continued to seek urologic care for their hematuria, protienuria and uremia.3 It was a return to the roots of nephrology at the turn of the 21 st century that refocused attention on kidney disease not as a fatal condition requiring replacement therapy, but as a clinical entity that is common, harmful, early to diagnosed and potentially treatable. 4

Chronic kidney disease $(\mathrm{CKD})$ prevalence is increasing world-wide and the prevalence of end-stage renal disease (ESRD) is expected to rise by $44 \%$ from 2000 to 2015.

Some of the proposed mechanisms of kidney damage are from uric acid include induction of afferent arteriolopathy, inflammation and activation of the renin-angiotensin system. ${ }^{2}$

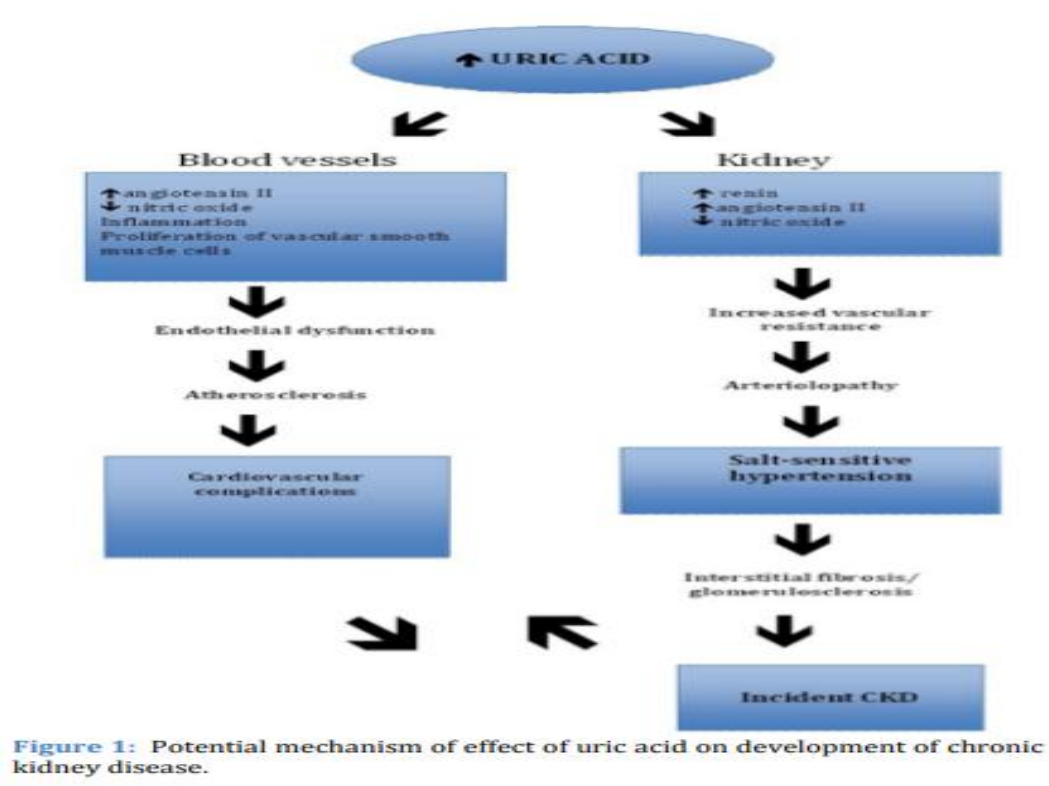

The pattern of disease morbidity and mortality throughout the world is changing both in the developed and the emerging world. The major cause of end-stage renal failure in most countries worldwide is now diabetes. India has the largest number of people with diabetes in the world, with the projected figures of 57.2 million cases in 2025 . This will make India the reservoir of CKD.9

The annual incidence of ESRD differs between developed and developing countries, $34-240$ per million population (pmp) to $98-198$ per million populations, respectively.10

Classification of CKD:

The KDOQI definition (2002) of CKD was accepted worldwide and given as follows:5 
Table 1:-Classification on severity of CKD

\begin{tabular}{|l|l|l|l|}
\hline Stage & Description & GFR ml/min/1.73m2 & Related items \\
\hline 1 & $\begin{array}{l}\text { Kidney damage with normal or } \\
\text { increased GFR }\end{array}$ & $>90$ & Albuminuria, proteinuria, hematuria \\
\hline 2 & $\begin{array}{l}\text { Kidney damage with mild reduction in } \\
\text { GFR }\end{array}$ & $60-89$ & Albuminuria, proteinuria, hematuria \\
\hline 3 & Moderate reduction in GFR & $30-59$ & Chronic renal insufficiency or early \\
\hline 4 & Severe reduction in GFR & $15-29$ & renal insufficiency \\
\hline 5 & Kidney failure & & Chronic renal insufficiency or late \\
\hline & & & renal insufficiency or pre ESRD \\
\hline & & & Renal failure, uremia, ESRD \\
\hline
\end{tabular}

Criteria for the Definition of Chronic Kidney Disease(CKD):

Kidney damage for 3 months as defined by structural or functional abnormalities of the kidney, with or without decreased GFR, that can lead to decreased GFR, manifest by either:

1. Pathological abnormalities; or

2. Markers of kidney damage, including abnormalities in imaging tests

3. GFR $<60 \mathrm{~m} 1 / \mathrm{min} / 1.73 \mathrm{~m} 2$ for 3 months, with or without kidney damage

\section{Materials And Methods:-}

The present study is a prospective study carried out on 158 CKD patients in ICU and Nephology Dept of Govt. General Hospital , Kurnool From June 2018 to may 2019. Formal approval of hospital ethical committee and written consent of the CKD patients were obtained for this study.

Patients satisfying the inclusion and exclusion criteria were enrolled into the study. Detailed clinical, biochemical, haematological examinations were conducted to establish the diagnosis and stage of CKD.

The present study was carried out on 158 adult patients of CKD (Chronic Kidney Disease). Out of which 60 CKD patients with raised serum uric acid were placed in study group were compared with age matched 98 CKD patients with normal serum uric acid.

\section{Inclusion Criteria:}

1. All the patients of both the sexes $>18$ years of age

2. All the diagnosed cases of chronic kidney disease.

\section{Exclusion Criteria:}

1. All the patients $<18$ years of age.

2. All HIV Positive individuals.

3. All the patients having history of gout and/or

4. Hyperuricemia.

5. Patients who are on anti tubercular drugs and thiazide diuretics.

\section{Diagnostic Criteria:}

All the patients were evaluated for chronic kidney disease (CKD) as per the KDOQI criteria (2002) by National Kidney Foundation for diagnosis of CKD.5

After confirmation of diagnosis from the above parameters, blood samples are drawn from these patients for the estimation of serum uric acid by Uricase method.

The study was designed to include the Demographic, clinical data, biochemical and haematological changes observed in CKD patients. The data was entered into a structured proforma separately. Management was done as per standard guidelines. 
Detailed clinical examination was done in all CKD patients. All these CKD patients were evaluated clinically for history of fever, easy fatigability, facial puffiness, swelling over extremities, nausea and vomiting, generalized bodyache, breathlessness, altered sensorium, convulsions, decreased urine output, haematuria, haemestemesis/malaena, pallor, pedal oedema, blood pressure and other vitals.

The laboratory investigations done in all CKD patients included a complete haemogram, fasting and postprandial blood sugar level, serum BUN, creatinine, eGFR, Serum potassium, calcium, serum uric acid, 24hrs urine albuminuria, HIV, Hepatitis B and C.

Detailed ultrasonography of abdomen and pelvis was done to check the size, shape and echo texture of the kidney.

\section{Statistical Analysis:-}

Data was analyzed by statistical Package for social sciences Version -16 (SPSS 16) software. Data was presented in frequency and percent distribution form. Association in between the parameters was tested using Pearson's chi square test. Mean values of parameters were compared between normal and raised uric acid levels in CKD patients using unpaired t-test. Mean comparisons of values of parameters in between patients with 5 stages of CKD were done by using ANOVA (Analysis Of Variance Test). P value less than 0.05 was considered as significant

\section{Results:-}

158 patients of documented CKD were taken and divided into 2 groups of which study group included 60 CKD patients with raised serum uric acid levels and comparison group included 98 CKD patients with normal serum uric acid levels. Statistical analysis showing results of study is given as follows:

Table 2:-Sex distribution according to Serum uric acid

\begin{tabular}{|l|c|c|c|}
\hline Sex & \multicolumn{2}{|c|}{ Serum uric acid } & Ttotal \\
\hline & Normal & Raised & 56 \\
\hline Female & 40 & 16 & 95 \\
\hline Male & 56 & 46 & 158 \\
\hline Total & 96 & 62 & \\
\hline
\end{tabular}

Status of patients with chronic kidney disease:






\section{Stages of CKD:}

In those with raised uric acid level, Maximum i.e. 54\% CKD patients had stage 5 CKD, 30\% had Stage 4 and $10 \%$ had Stage 3 CKD, 5\% had Stage 2 and 1\% has Stage 1 CKD. Of Normal uric acid level patients 28\% were in stage 5, 26\% were in stage 4 and $15 \%$ in Stage 3 while $16 \%$ in Stage 2 and $15 \%$ in Stage 1. There was statistically highly significant $(\mathrm{p}<0.01)$ difference with higher proportion of patients in higher Stage of CKD in raised uric acid group compared to normal uric acid group.

Table 3:- Stage of CKD according to Serum uric acid status of patients

\begin{tabular}{|l|l|l|l|l|}
\hline Stage of CKD & \multicolumn{1}{|c|}{ Serum uric acid } & \multicolumn{1}{|}{ Total } \\
\hline & Normal & \multicolumn{1}{|c|}{ Raised } & 16 \\
\hline 1 & 15 & 1 & 19 \\
\hline 2 & 16 & 3 & 21 \\
\hline 3 & 15 & 6 & 43 \\
\hline 5 & 25 & 18 & 59 \\
\hline Total & 32 & 158 \\
\hline & 27 & 60 & $100.00 \%$ \\
\hline & 98 & $100.00 \%$ & \\
\hline
\end{tabular}

Table 4:- Associated disorders according to Serum uric acid status of patients with chronic kidney disease

\begin{tabular}{|l|l|l|l|l|l|}
\hline Parameters & Serum uric acid & Total & X2 & P value \\
\hline & Normal & Raised & & & \\
\hline CKD with cardiovascular & & & & & \\
\hline Diseases & & & & & \\
\hline No & & & & & \\
\hline & 69 & 23 & 92 & 18.767 & $<0.001$ \\
\hline Yes & $75 \%$ & $25 \%$ & $100 \%$ & & \\
\hline & 21 & 33 & 54 & & \\
\hline CKD with anemia & $38.9 \%$ & $61.1 \%$ & $100 \%$ & & \\
\hline No & & & & & \\
\hline & 21 & 21 & 15.262 & $<0.001$ \\
\hline Yes & $23.3 \%$ & & $14.4 \%$ & & \\
\hline & 69 & 56 & 125 & & \\
\hline
\end{tabular}

Table 7:- Comparison of different parameters in CKD patients with raised and normal serum uric acid

\begin{tabular}{|l|l|l|l|}
\hline Parameter & \multicolumn{1}{|c|}{ Uric acid } & P value \\
\hline & Normal & Raised \\
\hline Age (yrs) & & & \\
\hline Sex(\% Male) & 52.97 & 54.07 & 0.604 \\
\hline SBP on & $58.9 \%$ & $78.6 \%$ & 0.027 \\
\hline Admission (mmHg) & 140 & 162 & $<0.001$ \\
\hline DBP on & & & $<0.001$ \\
\hline admission (mmHg) & 87 & \\
\hline Hypertension & & & 0.031 \\
\hline Fasting Glucose (mg/d1) & $70 \%$ & $<0.001$ \\
\hline Postprandial glucose (mg/dl) & 102 & $<5.7 \%$ & $<0.001$ \\
\hline HbA1C & 174 & 134 & 0.001 \\
\hline Diabetes mellitus & 5.47 & 220 & 0.011 \\
\hline Urine albuminuria (mg/dl) & $24.4 \%$ & $44.6 \%$ & $<0.001$ \\
\hline S BUN (mg/dl) & 390 & 1112 & $<0.001$ \\
\hline Creatinine (mg/dl) & 44.42 & 72.11 & $<0.001$ \\
\hline eGFR (ml/min/1.73m2) & 2.774 & 4.93 & $<0.001$ \\
\hline
\end{tabular}




\begin{tabular}{|l|l|l|l|}
\hline Anemia risk & $76.7 \%$ & $100 \%$ & $<0.001$ \\
\hline Cardiovascular risk & $23.3 \%$ & $58.9 \%$ & $<0.001$ \\
\hline Death & 0 & $14.3 \%$ & $<0.001$ \\
\hline & & & \\
\hline
\end{tabular}

\section{Discussion:-}

Previous studies have shown that serum uric acid is having independent role in progression of CKD and is also cause and predictor of associated morbidities in CKD.

Blood samples for measurement of serum uric acid level and other biochemical assessments were obtained immediately after admission. Uric acid concentration expressed in milligrams per deciliters (mg/dl). Male patients with uric acid concentration $>7 \mathrm{mg} / \mathrm{dl}$ and female patients with $>6 \mathrm{mg} / \mathrm{dl}$ were considered as having raised serum Uric acid. Furthermore for studying correlations of serum Uric acid with other clinical and investigational findings, all CKD patients were divided into two groups out of which one group included CKD patients with raised uric acid and other group included CKD patients with normal uric acid. Both groups were age matched.

There were 96 CKD patients with normal UA group and 62 patients in ckd with raised UA group were included in the study.

Serum UA level of ckd patients done on day of admission in both age matched groups were compared by t-test where its value $\mathrm{p}<0.05$ is considered as statistically significant. Thus patients who were having raised serum UA level was because of ckd and in both ckd groups derangement of other clinical and biochemical profiles were due to raised serum UA

The findings which we got in our study are discussed as follows:

Age:

In our study, we found that out of 158 CKD patients maximum that is $54 \%$ were within age group of 51-70 yrs. and $46 \%$ ckd patients were in age group of 31-50 yrs. This finding is consistent with findings of the study by Punamyadav et al, (2014), Madero et al, (2009) and George.S et al, (2013). It is observed that incidence of CKD reaches its maximum strength in later part of life.12-14

Sex:

In our study, (from Table 2), it is found that $78.6 \%$ males and $21.2 \%$ females were in ckd with raised UA group which shows statistically significant $(\mathrm{P}<0.027)$ difference of male predominance over females in ckd patients with raisedUA level. This finding in our study is consistent with findings in the studies by Nacak et al, (2014) \& Madero et al, (2009)

\section{Serum Uric Acid Levels In Relation With Severity Of Ckd}

In our study, (from Table 4, $6 \&$ 9), it is found that, there was statistically significant $(\mathrm{p}<0.01)$ correlation of raised serum uric acid with increasing stages of ckd, and it's severity. Serum uric acid was statistically significantly ( $<<0.001$ ) positively correlated with serum BUN, serum creatinine, and negatively correlated with eGFR, . In our study, ANOVA study also showed the statistically significant positive correlation between raised serum uric acid and progressively declining renal functions and severity of ckd. This finding in our study is consistent with the findings of studies by Chen et al, (2014)(, Mostafa Kamel et al, (2013)16, Nermina Babic et al, (2014), J. T. Park et al, (2009), where it is found that, this was statistically highly significant positive correlation of serum uric acid with stages and severity of ckd, duration of illness and marker of reduced renal functions like serum BUN and serum creatnine and negatively correlate with eGFR.

\section{Hypertension:}

In our study, (from Table 7), it is found that, significant proportion of hypertensive patients had come in CKD with raised UA group i.e., $85.7 \%$, and showingstatistically significant positive correlation $(\mathrm{p}=0.031)$ of UA with hypertension, this finding is consistent with the findings of studies by J. T. Park et al, (2009), Paul et al , (2012) and Liu WC et al, (2012). It is found that, there is statistically significant higher systolic BP $(\mathrm{P}<0.001)$ and diastolic $\mathrm{BP}(\mathrm{P}<0.001)$, in raised UA CKD patients than normal UA CKD patients. This findings are consistently matched with findings of studies by B. Satirapoj et al, (2010) and Mostafa Kamel et al, (2013). 


\section{Diabetes Mellitus:}

In our study, (from Table 7), it is found that, there was statistically significant positive difference of diabetes ( $\mathrm{p}=0.011$ ) in CKD patients with raised uric acid level (44.6\%) than normal uric acid level $(24.4 \%)$ in CKD patients. Also, serum uric acid has statistically significant positive correlation $(\mathrm{p}<0.001)$ with both fasting and post prandial blood sugar level. This finding in our study is consistently matched with the findings of studies by J. T. Park et al, (2009), Adel Gouri et al, (2013) and Liu WC et al, (2012).15-30

\section{Conclusion:-}

In CKD patients, higher serum uric acid levels were associated with higher degree of renal dysfunction, hypertension, diabetes, urine albuminuria, anaemia, cardiovascular disease/ events and mortality. It is found that most common cause of mortality in CKD patients with raised serum uric acid was cardiovascular disease/events.

\section{References:-}

1. Dharan KS, John GT, Neelakantan N, Korula A, Balakrishnan N, Kirubakaran MG, Jacob CK. Spectrum of severe chronic kidney disease in India: a clinicopathological study Natl Med J India. 2006 Sep-Oct; 19(5):2502.

2. Filiopoulos V, Hadjiyannakos D, and Vlassopoulos D. New insights into uric acid effects on the progression and prognosis of chronic kidney disease. Ren Fail. 2012, 34(4): p. 510- 20. 12.

3. Eknoyan G. Rememberance of things past. Port J NephrolHypert. 2011; 25(4): 239-245.

4. Levey AS, Andreoli SP, Dubose T, Provenzano P, Collins AJ. Chronic KidneyDisease: common, harmful and treatable. World kidney day, 2007. J Am SocNephrol. 2007; 18(2):374378-.

5. National Kidney Foundation. K/DOQI Clinical Practice Guidlines for

6. Chronic Kidney Disease: evaluation, classification and stratification. Am J

7. Kidney Dis. 2002; 39(2) (suppl 1):S18266-.

8. Eknoyan G. Chronic kidney disease: the quest for refinements. idney Int.2007; 72(10): 1183-1185.

9. Gilbertson DT, Liu J, Xue JL et al. Projecting the number of patients with end-stage renal disease in the United States to the year 2015. J Am SocNephrol 2005; 16: 3736-3741.

10. Robert C. Atkins, Department of Nephrology, Monash Medical Centre, Clayton, Victoria, Australia, The epidemiology of chronic kidney disease, Kidney International, Vol. 67, Supplement 94 (2005), pp. S14-S18.

11. King H, Aubert RE, Herman WH. Global burden of diabetes 1995 -2025: prevalence, numerical estimates, and projections. Diabetes Care. 1998;14141431.

12. Kher V. End-stage renal disease in developing countries. Kidney Int. 2002;350-362.

13. SK, Dash SC, Irshad M et al. Prevalence of chronic renal failure in adults in Delhi, India. Nephrol Dial Transplant. 2005; 20: 1638-1642.

14. Joshi R, Magnolia C, Srinivas I, et al. Chronic diseases now leading cause of death in rural India-mortality data from the Andhra Pradesh rural health initiative. Int J Epidemiol, 2006;35 (6):1522-9.

15. Rosenfeld, L. Four Centuries of Clinical Chemistry. New York: Taylor and Francis; 1999.

16. Behrend Robert (1925). "ZurGeschi chte der Hamsauresynthesen" Justus

17. LiebigsAnnalen der Chemie(in German) (Weinheim, BadenWurtte- $m$ berg, Germany: WILEY-UCH VerlagGmbH and Co. KGaA) 441(1): 215-216.

18. McCrudden, F. Uric acid: the chemistry, physiology andpathology of uric acid and the physiologically important purine bodies, with a discussion of the metabolism in gout. Paul Hoeber Medical Books; 1905.

19. Haig A. Uric acid as a factor in causation of disease. London: J and A Churchill; 1897.

20. Alexander So and Bernard Thorens, Uric acid transport and disease, J Clin Invest. 2010;120(6):1791-1799.

21. Dennis J. Levinson And Leif B. Sorensen, Renal handling of uric acid in normal and gouty subjects: evidence for a 4-component system, Annals of the Rheumatic Diseases, 1980, 39, 173-179.

22. Choi HK, Mount DB, Reginato AM, American College of Physicians \& American Physiological Society Pathogenesis of gout. Ann. Intern. Med. 2005;143:499-516.

23. Joanne Bargman, Karl Skorecki. Harrison's principle of Internal medicine, 18th Edition, Chapter 280 Chronic Kidney Didease, p 2308.

24. Y. Y. Sautin and R. J. Johnson, "Uric acid: the oxidantantioxidant paradox," Nucleosides, Nucleotides and Nucleic Acids, vol. 27, no. 6-7, pp. 608-619, 2008.

25. Johnson RJ, Kang DH, Feig D, Kivlighn S, Kanellis J, Watanabe S, et al. Is there a pathogenetic role for uric acid in hypertension and cardiovascular and renal disease? Hypertension 2003; 41: 1183-1190. 
26. Diana I. Jalal, Michel Chonchol, Wei Chen, and Giovanni Targher, Uric Acid as a Target of Therapy in CKD, Am J Kidney Dis. 2013 January; 61(1): 134-146.

27. Daniel I. Feig, Uric acid - a novel mediator and marker of risk in chronic kidney disease?,CurrOpinNephrolHypertens. Author manuscript; available in PMC 2010 November 1.

28. D.-H. Kang, T. Nakagawa, L. Feng et al., "A role for uric acid in the progression of renal disease," Journal of the American Society of Nephrology, vol. 13, no. 12, pp. 2888-2897,2002.

29. D.-H. Kang, S.-K. Park, I.-K. Lee, and R. J. Johnson, "Uric acid-induced C-reactive protein expression: implication on cell proliferation andnitric oxide production of human vascular cells," Journal of the American Society of Nephrology, vol. 16, no. 12, pp. 3553-3562,2005.

30. JayantaPaul, SomnathDasgupta, Association of Hyperuricemia With Carotid Intima-Media Thickness, Albuminuria,Diabetes, Hypertension in Chronic Renal Failure, World J Nephrol Urol. 2012;1(2-3):66-72.

31. M. Busuioc, L. Voroneanu, S. Hogas, M. Covic, P. GusbethTatomir- and A. Covic, Pathogenetic Impact of Hyperuricemia in Renal and Cardiovascular Disease, BANTAO Journal 2007: 5 (1): 1.

32. Punam Yadav, Dinkar Malik, SandeepKuma, Vijai Malik, A Role Of Serum Uric Acid In Chronic Renal Failure Patients And Its Effects, International

33. Journal Of Scientific Research And Education, Volume 2 Issue 3 Pages 434-442 2014 ISSN (e): 2321-7545.

34. Magdalena Madero, Mark J Sarnak, Xuelei Wang, Tom Greene, Gerald J Beck, John W Kusek, Allan J Collins, Andrew S Levey, and VandanaMenon, Uric Acid and Long-term Outcomes in CKD, Am J Kidney Dis. 2009 May; 53(5): 796-803. 